\title{
ARTIGOS
}

\author{
Submetido 03.10.2020. Aprovado 05.05.2021
}

Avaliado pelo sistema double blind review. Editor Científico: Maurício Serva

Versão original | DOI: http://dx.doi.org/10.1590/So034-759020220202

\section{RACIONALIDADE SUBSTANTIVA NA GESTÃO COMUNAL DE ECOVILAS}

\author{
Substantive rationality in communal ecovillage management \\ Racionalidad sustantiva en la gestión comunal de ecovillas \\ Guilherme Smaniotto Tres ${ }^{1}$ | guis3@hotmail.com | ORCID: 00oo-0001-9765-7524 \\ Washington José de Souza1 | wsufrn@gmail.com | ORCID: 0000-0001-6295-2806
}

1Universidade Federal do Rio Grande do Norte, Departamento de Administração, Natal, RN, Brasil

\section{RESUMO}

Abordamos elementos de racionalidade substantiva na prática administrativa, em organizações produtivas, via atributos de gestão comunal em atividades de produção agrícola e de cuidado com a vida natural e humana em ecovilas. De inspiração etnográfica, visitamos quatro ecovilas durante 49 dias, acompanhando o cotidiano e relações de trabalho. Os resultados apontam que rotinas de gestão enfatizam a reprodução social sob princípios de autossuficiência. 0 compartilhamento da terra e dos meios de produção e a orientação ao cuidado coletivo compõem ambiente de segurança social e econômica a partir de laços comunais voluntariamente constituídos. Predominam processos de gestão com viés de racionalidade substantiva que interconectam demandas e militância ecológica a ações de mitigação da degradação ecológica e de valorização da diversidade da vida, caracterizando traços de práticas administrativas emancipatórias do ser humano na esfera produtiva em organizações privadas.

PALAVRAS-CHAVE | Ecovilas, organizações substantivas, racionalidade substantiva na prática administrativa, agroecologia, gestão comunal.

\section{ABSTRACT}

We approach elements of substantive rationality in administrative practice, in productive organizations, through attributes of communal management in agricultural production activities and care for natural and human life in ecovillages. Inspired by ethnography, we visited four ecovillages for 49 days, following daily life and working relationships. The results show that management routines emphasize social reproduction under principles of self-sufficiency. The sharing of land and the means of production and the orientation to collective care comprise an environment of social and economic security based on voluntary community bonds. Prevail management processes with a bias of substantive rationality that interconnect demands and ecological activism with actions to mitigate ecological degradation and enhance the diversity of life, characterizing traces of human emancipatory administrative practices in the productive sphere in private organizations.

KEYWORDS/ Ecovillages, substantive organizations, substantive rationality in administrative practice, agroecology, communal management.

\section{RESUMEN}

Este artículo investiga los elementos de racionalidad sustantiva en la práctica administrativa, en organizaciones productivas, a partir de atributos de gestión comunal en las actividades de producción agrícola y cuidado de la vida natural y humana en las ecoaldeas. Inspirándonos en la etnografía, visitamos cuatro ecoaldeas durante 49 días, siguiendo la vida cotidiana y las relaciones de trabajo vigentes. Los resultados muestran que las rutinas de gestión enfatizan la reproducción social bajo principios de autosuficiencia.. La compartición de la tierra y los medios de producción y la orientación al cuidado colectivo conducen a un ambiente de seguridad social y económica basado en los lazos comunales. Predominan los procesos de gestión con un sesgo de racionalidad sustantiva que interconectan las demandas y la militancia ecológica con acciones para mitigar la degradación ecológica y valorar la diversidad de la vida, con rasgos de prácticas administrativas emancipadoras del hombre en la esfera productiva en organizaciones privadas.

PALABRAS CLAVE I ECoaldeas, organizaciones sustantivas, racionalidad sustantiva en la práctica administrativa, agroecologia, gestión comunal. 


\section{INTRODUÇÃO}

A partir de ideais de preservação e regeneração do meio ambiente natural e de harmonia entre ser humano e natureza, abordamos organizações - ecovilas - que evoluem contemporaneamente como lócus de experimentação de práticas contra-hegemônicas de vida, e, de modo específico, de gestão. A vida em comunidade, por si, é suficiente para caracterizar movimento contra-hegemônico quando reconhecemos que a contemporaneidade é marcada pelo narcisismo exacerbado e pela atomização do indivíduo (Han, 2017) em dinâmicas de vida mercadocêntrica (Ramos, 1981) que degradam a vida, o ser humano e o meio ambiente natural.

Práticas organizacionais em ecovilas, aqui pautadas, evidenciam sentimentos de emancipação humana mediante viés que, no domínio da Ciência Administrativa, encontra bases em Guerreiro Ramos (1981) e Serva (1997), por revelarem relações de trabalho e produção com características de isonomias/fenonomia. Reportamos estruturas e dinâmicas peculiares, articulações entre múltiplas possibilidades econômicas e trabalho orientado à autossuficiência, que denominamos gestão comunal.

Serva (1997), ao introduzir no Brasil o debate da emancipação humana no domínio dos Estudos Organizacionais, abordou o impasse representado pela ausência de evidências da racionalidade substantiva em práticas administrativas. As ecovilas contribuem para o debate e, do mesmo modo que Serva (1997), revelam impasses na construção da racionalidade substantiva na prática administrativa em organizações de natureza privada. Organizações produtivas, em geral, adotam processos administrativos baseados na racionalidade instrumental nos termos da crítica de Guerreiro Ramos (1981). Desse modo, a superação de relações humanas, econômicas, sociais, e, portanto, de técnicas convencionais de gestão, virá por outro modo de interpretar o mundo e de agir. Como Serva (1997), pautamos organizações privadas que permitem atualização pessoal em sintonia com autorrealização, o que as torna espaços sociais autogratificantes. Igualmente, adotamos exercício metodológico etnográfico baseado em variáveis tipicamente administrativas.

Nosso lócus são empreendimentos privados que estabelecem conexão com práticas ecológicas, com especificidades rurais de trabalho e produção orientadas à reprodução social. Em sentido amplo, abordamos emancipação humana - em conexão com a crise ambiental e social sob viés não utilitário - fundamentada em experiências organizacionais de vida e de trabalho em bases comunitárias. Partimos, para tanto, da seguinte questão: Como processos de gestão comunal em comunidades intencionais ecológicas evidenciam práticas de organizações substantivas?

Serva (1993) reconheceu que organizações substantivas adotam, predominantemente, uma racionalidade que habilita o indivíduo a ordenar a vida eticamente, a partir de ações que intentam harmonia dinâmica entre satisfação pessoal e satisfação social, e autorrealização, pela concretização de potencialidades humanas. Diferentemente do autor, que estudou empreendimentos do setor de serviços, arrolamos práticas organizacionais substantivas centradas na reprodução social coletiva a partir de viés ecológico.

Estudos sobre a racionalidade substantiva vêm sendo desenvolvidos em vários contextos. Araujo, Paiva, Souza e Momo (2013) delinearam, junto a trabalhadoras rurais da reforma agrária, ambiente isonômico em vivências econômico-solidárias. Birochi, Vivan e Granzotto (2019), em fábricas de alimentos do movimento slow food na Grande Florianópolis, traçaram faces divergentes de organizações em redes agroalimentares com base na abordagem substantiva das organizações. Tal perspectiva teórica, todavia, ultrapassa o setor produtivo e encontra registro de aplicação em pesquisa de projetos pedagógicos, como em Silva e Silva (2020), que sintetizaram formas manifestas da racionalidade substantiva em currículos de cursos do ensino médio integrados à educação profissional. 
Serva, Caitano, Santos e Siqueira (2015) reuniram artigos científicos que adotaram o modelo analítico pioneiro de Serva (1997), pontuando que, com 38 registros, os estudos sobre a racionalidade nas organizações avançaram no Brasil. A aplicação inclui um diversificado leque de organizações como instituição psiquiátrica, operadora de plano de saúde, empresas de economia de comunhão, cooperativas, mosteiro, empresa do setor elétrico em ação de responsabilidade social, rede de economia solidária e também no setor educacional. A análise validou a contribuição do modelo para o campo dos Estudos Organizacionais, reforçando a validade dessa linha e abrindo possibilidades de pesquisas a partir do pensamento de Guerreiro Ramos.

Uma visão de abundância, de trabalho e de produção agrícola coletivos ancora-se no entendimento da natureza como parte da vida humana, e não como mercadoria. Sob apelo ecológico "que pouca gente se dá conta" na obra de Guerreiro Ramos (Tenório, 2014, p. 45), organizações privadas no setor de produção agropecuário revelam práticas administrativas alternativas, de racionalidade substantiva, conferindo relevância a este artigo no âmbito dos Estudos Organizacionais.

\section{ATRIBUTOS DE RACIONALIDADE E DA GESTÃO COMUNAL}

O conceito e o movimento de ecovilas realçam compromisso com a diversidade da vida humana alinhado a valores ideais de respeito ao meio ambiente natural (Cunha, 2012; Santos, 2006). Sendo um tipo específico de comunidade intencional, as ecovilas incorporam, além do apelo ambiental, medidas de autossuficiência, movimentos “de volta para a terra” (Dawson, 2004), de coabitação e educação alternativas. Orientadas pela vida comunal, revelam espectros de trocas sociais que favorecem o desenvolvimento humano em diversas dimensões, tanto físicas, emocionais e mentais quanto espirituais (Gilman, 1991). Elementos presentes a uma racionalidade que, em essência, depura o cálculo utilitário de ganho e perda.

As ecovilas estimulam debates e ações para conter a degradação do meio ambiente natural por perdas na fertilidade do solo, biodiversidade e qualidade da água, e em saúde coletiva e segurança e soberania alimentar e nutricional (SSAN). Alimentos frescos, colhidos na horta das próprias comunidades ou trocados com vizinhos, conferem significado à SSAN, revelando bem-estar comunitário com base na autonomia para decidir o que produzir, para quem produzir e em que condições produzir.

À medida que a lógica capitalista orienta comportamentos, não para suprir necessidades humanas, mas para a valorização do capital (Antunes, 2018), a natureza torna-se mercadoria como qualquer outra. A agricultura adquire aspectos estritamente de mercado (Shiva, 2003), e o seu ciclo natural é apropriado pelo capital (Altieri, 1998). As ecovilas contestam tal perspectiva hegemônica de vida a partir da relação humana com a terra em termos exclusivamente financeiros.

Princípios da agroecologia, permacultura, produção orgânica de alimentos, energia limpa, destinação, reaproveitamento e reciclagem de resíduos e economia solidária estão na pauta do enfrentamento da crise ambiental pelas ecovilas (Comunello, 2016). 0 entendimento de mutualidade entre ser humano e meio ambiente natural sustenta práticas de trabalho orientadas à autossuficiência e ao suprimento de necessidades humanas nas ecovilas. Trata-se de prática organizacional emancipatória ancorada em

cenários adequados à atualização pessoal, a relacionamentos de convivência e a atividades comunitárias dos cidadãos. Uma sociedade assim requer também iniciativas partidas dos cidadãos, que estarão saindo da sociedade de mercado sob sua própria responsabilidade e sob seu próprio risco. (Ramos, 1981, p. 155). 
Tais cenários habilitam o indivíduo a distinguir entre o bem e o mal e entre o conhecimento falso e o verdadeiro no ordenamento da vida pessoal e social (Ramos, 1981). É no Paradigma paraeconômico que Guerreiro Ramos (1981) sintetiza uma abordagem multicêntrica de alocação de recursos na sociedade e delimita sistemas sociais. Nele, a isonomia é enclave de mediação entre prescrição e ausência de normas com orientação comunitária.

Definida como contexto organizacional em que todos os membros são iguais, a isonomia contém: 1) prescrição mínima de normas, e, quando necessário, estabelecidas por consenso; 2) realização de atividades autogratificantes, proporcionando aos membros um tipo generoso de relacionamento social; 3) atividades realizadas como vocação, e não como prática de esforços subordinados às necessidades objetivas inerentes ao processo de produção em si; 4) sistema de tomada de decisão e de fixação de diretrizes políticas abrangente, sem relações hierárquicas; 5) relações interpessoais primárias em detrimento de relações formais. Práticas organizacionais com tais qualidades derivam-se de iniciativas espontâneas

[...] em tomo de ideais e princípios determinantes de ações conjuntas as quais, por sua vez, acabam configurando práticas sócio-organizacionais relativamente descompromissadas com o estatuto essencialmente sistêmico da sociedade burocratizada. (Serva, 1993, s/p).

São, pois, tais elementos que se mostram válidos à qualificação das comunidades intencionais ecológicas como organizações substantivas. Ainda que Serva (1993) tenha constatado a presença de racionalidade substantiva em organizações produtivas (de serviços), em ecovilas, esses estudos são discretos. Siqueira (2012; 2017) abordou o tema via tensões entre racionalidade substantiva e instrumental, todavia, em unidade que incorporou diretrizes ecológicas sob formato de condomínio, mediante acordos particulares. Trata-se de uma noção de ecovila que não se assemelha àquela aqui pautada, pois, apesar das intenções que ao longo do tempo surgiram, a organização pesquisada não estava orientada à vida comunal e ao compartilhamento dos meios de produção e de resultados do trabalho.

O compartilhamento é atributo relevante à definição de um quadro analítico para o estudo da racionalidade na prática administrativa em ecovilas, tanto pelo viés econômico (solidário) quanto pelo poder na criatividade organizacional (Carlsen, Clegg, Pitsis, \& Mortensen, 2020). Carlsen et al. (2020) defendem que a criatividade organizacional deve, antes de tudo, viabilizar conexão, abundância e agência coletiva, contrapondo-se a práticas de poder sobre, relacionadas a pressupostos de linearidade e singularidade da criatividade. A partir do ponto de vista dos autores, podemos pontuar que, nas ecovilas, se perpetram poder com e poder de em dinâmicas relacionais e processuais que integram ser humano e meio ambiente natural. Ideais de poder com e poder de requerem processos de enquadramento interacionais por meio dos quais as pessoas atendem conjuntamente a demandas organizacionais e alcançam novas integrações e realidades sociais (Carlsen et al, 2020).

A racionalidade manifesta-se mediante objetivos ordenados na relação consciente de significados e valores. Weber (1994) considera racionalidade formal o grau de cálculo tecnicamente possível e realmente aplicado, e considera racionalidade material o grau em que o abastecimento de bens de determinados grupos, em ação economicamente orientada, ocorre pelo modo como um empreendimento é, foi ou poderá ser julgado. É razoável considerar que a racionalidade material, no sentido de suprimento de necessidades, e a racionalidade formal, no sentido de decisão voltada a fins, têm naturezas e propósitos distintos. 
A multiplicidade de trocas nas ecovilas revela racionalidade material conectada a propósitos de autossuficiência. Evidencia práticas de economia plural com predominância de domesticidade e reciprocidade (Polanyi, 2000). Reciprocidade aparece em trocas voluntárias materializadas em práticas difusas e interações intersubjetivas, e não em benefícios econômicos de caráter financeiro-monetário (Polanyi, 200o). Simetria é o princípio norteador, aderente à isonomia. Domesticidade, por sua vez, consiste na produção para uso próprio e/ou coletivo com motivações que não se apoiam em ganho, em critérios e instituições de mercado. 0 ato de produzir e armazenar é centrado na satisfação de necessidades de grupo, família, localidades, ou poder político, como no castelo senhorial (Polanyi, 2000). O princípio norteador é autarquia, uma concepção de autossuficiência.

Nas ecovilas, a centralidade na preservação e regeneração de ecossistemas e no bem-estar coletivo manifesta-se sob formas de agricultura natural, multicêntrica, alinhadas a práticas administrativas substantivas. Em síntese, tomamos ecovila como organização orientada à reprodução social, com estrutura organizacional horizontal, flexível, processos decisórios isonômicos, trocas sociais entre seres humanos, e destes com o meio ambiente natural, intencionadas à autossuficiência via práticas agrícolas naturais. Da articulação dessas qualidades, advém o que chamamos de gestão comunal. O Quadro 1, a seguir, apresenta as referência à análise da gestão comunal.

Quadro 1. Quadro de referência à análise da gestão comunal

\begin{tabular}{l|c|c}
\hline \multirow{2}{*}{ Categoria } & Organizações centradas no mercado & Gestão comunal \\
\hline \multirow{2}{*}{ Orientação } & Reprodução do capital & Reprodução social \\
\cline { 2 - 3 } & Dependência do mercado & Autossuficiência \\
\hline Estrutura organizacional & Vertical, hierárquica & Horizontal, flexível \\
\hline Processo decisório & Níveis distintos de autoridade & Relações isonômicas \\
\hline Relações econômicas & Trocas monetárias & Trocas sociais \\
\hline Relação com o ecossistema & Monocultura agrícola & Agricultura natural \\
\hline
\end{tabular}

Fonte: elaborado pelos autores

\section{O PERCURSO DE INSPIRAÇÃO ETNOGRÁFICA}

A etnografia, originária da Antropologia e posteriormente acatada por outras áreas do conhecimento, mostrou-se útil ao propósito de revelar práticas de gestão de sistemas de trabalho e produção centrados na autossuficiência com apelo ecológico. Tres e Souza (2019) evidenciaram que a pesquisa em ecovilas faz amplo uso da etnografia, a exemplo de Sinisterra (2013), Souza (2016) e Comunello (2016), explicada pelo interesse da descrição da realidade social e de sua produção (Flick, 2008) em investigação de fenômenos in situ (Moisander \& Valtonen, 2006) - quando o pesqui- 
sador acessa o mundo natural, participa da vida cotidiana do grupo pesquisado e é por ele reconhecido como igual (Mariampolski, 1999). Essa relação de confiança é fundamental ao sucesso da pesquisa etnográfica (Barros, 2007).

A coleta dos dados em quatro comunidades ocorreu via recursos da etnografia. Um dos autores deste artigo participou da vida diária das comunidades como voluntário. Alertamos para o fato de que períodos de imersão no campo, na etnografia, duram de meses a anos. Assim, assumimos, nos termos de Pinheiro (2019), uma abordagem de inspiração etnográfica.

Os critérios definidos para a escolha das comunidades foram: 1 - autorreconhecimento como comunidade ou ecovila; 2 - pelo menos cinco anos de formação; 3 - pelo menos 10 membros ou associados; 4 - algum grau de compartilhamento de propriedade; 5 - praticar agricultura natural. 0 critério 1 intentou recorte conceitual, uma vez que ecovila possibilita compreensões diversas. Os critérios 2 e 3 delimitaram comunidades com certo grau de complexidade nas relações interpessoais e experiência no manejo de sistemas produtivos com propósito de autossuficiência. 04 assume que ecovila engendra compartilhamentos de meios de produção e propriedade a fim de instituir relações isonômicas - critério imprescindível à gestão comunal. 05 conecta-se aos vieses de vida orientada à preservação e recuperação do meio ambiente natural e de trabalho para a reprodução social.

As ecovilas selecionadas foram: Comunidade Campina, Floresta de Iroko, Ecovila Tibá e Source Temple Sanctuary - todas rurais. A coleta dos dados, com apoio de diário de campo, ocorreu em 49 dias. Seguindo a orientação de Elliott e Jankel-Elliott (2003) quanto a estudos etnográficos, procedemos à coleta de qualquer tipo de dado que subsidiasse a análise, como documentos, características locais, histórico de eventos regionais e ações desenvolvidas pelas comunidades etc. Arquitetura, áreas de cultivo e reserva ambiental, fauna, flora e particularidades também foram registradas (por meio de fotografias) nesse sentido.

Tibá cedeu o estatuto, Floresta de Iroko, o estatuto e o documento "Coordenação geral”, Source Temple indicou visita ao website https://sourcetemple.one/ (por não haver regimento interno nem documento de qualquer natureza), idem na Campina (website www.comunidadecampina.org). Entrevista semiestruturada foi realizada com representante de cada ecovila e gravada mediante anuência via Termo de Consentimento Livre e Esclarecido (TCLE). A coleta contemplou entrevista com um membro da Campina (duração de 20 minutos), um da Ecovila Tibá (duração de 30 minutos) e um do Source Temple (duração de 43 minutos). Exceção ocorreu na Floresta de Iroko, onde a coleta envolveu a totalidade dos membros, devido ao número reduzido de habitantes no período da coleta.

Além de fonte para triangulação de dados, conforme sugere Yin (2015), a entrevista propiciou verificação do alinhamento entre discurso e prática, recuperação de trajetórias comunitárias e esclarecimentos da infraestrutura disponível, funcionamento e valores comunitários. A sessão de entrevista ocorreu nos últimos dias da estadia em cada comunidade, para facilitar compreensões e dirimir dúvidas.

Todos os moradores e moradoras foram informados de que nenhum nome seria divulgado. Desse modo, as referências são aqui feitas por meio de gentílicos - uma pessoa campineira, templária, tibaense, floresteira. Após a fase de organização dos dados e análise pelos pesquisadores, um informante de cada comunidade foi convidado à validação da sistematização procedida.

A Tabela 1 sintetiza itens relevantes à caracterização geral das unidades pesquisadas. A Campina tem origem em um grupo de 12 pessoas que decidiu viver de maneira integrada com o meio ambiente natural, em vida comunitária. O grupo reunia-se uma vez por semana para estudos sobre espiritualidade e ecologia, quando percebeu que precisava praticar. Após um integrante adquirir uma propriedade, todos reuniram-se para instalar a comunidade. 
Tabela 1. Dados gerais das ecovilas da pesquisa

\begin{tabular}{|c|c|c|c|c|}
\hline Item & Tibá & Campina & Floresta de Iroko & Source Temple \\
\hline Orientação & Ecológica & Ecológica & Ecológica & Religiosa \\
\hline Localização & São Carlos/SP & Palmares/BA & Itacaré/BA & Cunha/SP \\
\hline Fundação (ano) & 2006 & 1991 & 2013 & 2010 \\
\hline Número de membros & 30 & 19 & 6 & 40 \\
\hline $\begin{array}{l}\text { Número de } \\
\text { residências }\end{array}$ & 9 & 11 & 3 & 29 \\
\hline Data da coleta & $\begin{array}{c}\text { de } 27 / 8 / 2019 \text { a } \\
7 / 9 / 2019\end{array}$ & $\begin{array}{c}\text { de } 16 / 7 / 2019 \text { a } \\
26 / 7 / 2019\end{array}$ & $\begin{array}{c}\text { de } 28 / 7 / 2019 \text { a } \\
11 / 8 / 2019\end{array}$ & $\begin{array}{c}\text { de } 14 / 8 / 2019 \text { a } \\
24 / 8 / 2019\end{array}$ \\
\hline Dias de coleta & 12 & 11 & 15 & 11 \\
\hline Área (hectare) & 25 & 188 & 35,8 & 24 \\
\hline Propriedade & Coletiva & Coletiva & Coletiva & Coletiva \\
\hline
\end{tabular}

Fonte: elaborado pelos autores

Floresta de Iroko tem igualmente origem em grupo de amigos com propósitos ecológicos, e, assim, em 2016, implantaram o projeto. Compraram três fazendas vizinhas, consolidando-as em uma. 0 grupo constituía-se como associação informal até a data da revisão final deste artigo, março de 2021. Todavia, há estatuto com processos de decisão, assembleias, compra e venda de cotas, destinação das áreas comuns e zoneamento da propriedade, com ênfase em plantio e regeneração da floresta e da mata ciliar.

A Tibá tem origem em conversas entre amigos sobre problemas ambientais e como superá-los. Tyba é sufixo de abundância, de coletivo na língua Tupi. Adota o lema "crescer na diversidade", o que expressa, apropriadamente, motivações de um grupo heterogêneo que reúne professores universitários, estudantes, trabalhadores da iniciativa privada e empresários. Tem natureza jurídica de associação sem fins lucrativos. A posse da área está em nome da associação, e cada sócio detém cota com participação igualitária.

A Source Temple Sanctuary originou-se em residência em área urbana na Espanha. Em 2010, uma templária, que possuía propriedade rural no Brasil, sugeriu a mudança ao grupo e doou a área sob a forma jurídica de igreja. A comunidade tem base espiritual e identifica-se como centro espiritual não denominacional. Os membros usam variados símbolos para afirmar que a "mente é única e a consciência é singular, sempre plenamente integradas". A pauta ambiental é, assim, indissociável da motivação espiritual.

\section{A GESTÃO COMUNAL EM ECOVILAS}

Os resultados aqui apresentados estão na ordem do Quadro 1. Ainda que apresentadas separadamente, o conjunto das categorias é indissociável, de tal modo que os registros selecionados devem ser percebidos em sua totalidade. Quando pertinentes, pontuamos impasses, tensões, conflitos e medidas de superação adotadas. 
Apontamos elementos, práticas e evidências que configuram a gestão comunal em bases substantivas, e não critérios ou normas estritamente fixados. A gestão orienta-se por relações de solidariedade, aprendizagens coletivas, cooperações intra e intercomunitárias, compartilhamento de terra e meios de produção, além de militância ecológica, educação ambiental e construções naturais. Ecologia e isonomia, fundamentos que Tenório (2014) destaca em Guerreiro Ramos (1981), ancoram práticas de organizações substantivas e congregam requisitos que denominamos gestão comunal.

\section{Reprodução social e autossuficiência}

Nas quatro comunidades, processos de gestão, trabalho e produção afastam-se de finalidades mercadocêntricas. São nítidas a orientação ética e a autenticidade, apontadas por Serva (1997) como elementos de organizações substantivas, inclusive pela avaliação de meios adequados ao entrelaçamento entre demandas ambientais e agricultura baseada em vocações regionais e em práticas agroecológicas para a autossuficiência.

A orientação política para estilo de vida compartilhado preserva ciclos da natureza com rotinas interconectadas a trabalho, aprendizagem e lazer. Uma floresteira afirmou: "Hoje em dia, as pessoas separam o trabalho da diversão. Não se consegue ter prazer no trabalho; do jeito que o trabalho é, ele afasta as pessoas. Aqui, a gente sente de outra forma e vem melhorando". Evidenciando trabalho gratificante para suprir demandas coletivas, a floresteira exprime entendimento, elencado por Serva (1997) como requisito da racionalidade substantiva na prática administrativa,

Fontes de trabalho e renda emergem de visitas, programas de voluntariado, oferta de cursos, educação ambiental e venda de excedentes de produção, especialmente de itens alimentícios. São arrecadações pontuais, não estratégias de mercado. 0 trabalho é, em geral, de quatro horas diárias, entre cinco e seis dias por semana. Considerando que a atividade rural de cuidado com plantação e animais exige trabalho constante, tal imperativo é atenuado por revezamentos.

Se, para Antunes (2018), na lógica capitalista, o trabalho não enfatiza suprimentos de necessidades humanas, nas comunidades, são elas que estruturam ações. Cuidado com hortas, jardins, preparo das refeições, programação de eventos, manutenção, além de cuidado com crianças e idosos, ajustam-se ao tempo livre. Há profissionais como professores, guias turísticos, construtores, comerciantes, funcionários públicos, artistas e outras ocupações, que exercem atividades externas intercaladas com períodos dedicados à comunidade.

A orientação para autossuficiência foi incorporada ao longo do tempo na Source Temple, fortalecendo laços com o entorno. Uma templária registrou que: "No começo de 2019, vimos que não podíamos mais investir na horta por questões financeiras, e surgiu até mesmo a ideia reduzi-la. Eu me opus e disse que deveríamos ampliá-la". Surgiu, então, tensão na escolha entre ir ao mercado ou dedicar mais força de trabalho para suprir as necessidades do grupo. Tal debate, constatamos, evidencia que a presença ou preponderância da racionalidade substantiva não pressupõe permanente pacificação, de tal modo que a decisão foi tomada porque:

Se fôssemos comprar tudo que a horta nos dá, seria um custo muito alto para comer na qualidade que temos. Tudo sem agrotóxico. Quase todos os dias é alimento para 30-40 pessoas. Teríamos que ficar mais dependentes das coisas externas, como cursos/eventos. (Templária). 
A declaração ilustra que conflitos ocorrem em torno de decisões para benefício comum, e não ganhos individuais. A Campina igualmente revela conflitos, mitigados por processo particular de comunicação. Uma campineira ponderou: "A gente precisa organizar melhor, e as pessoas querem trabalhar mais aqui e ter mais renda aqui de dentro, sem precisar ir lá fora”. Novamente, o embate aparece entre autossuficiência e relação com o mercado. Esse tipo de tensão, na Campina, é conduzido mediante princípios de comunicação não violenta. Semanalmente, uma pessoa traz o tema à discussão a partir de registros de acontecimentos: "Nos ajuda a saber mais sobre nossos sentimentos e a cuidar melhor de nós mesmos para fazer o que nos propomos aqui".

Em maio de 2020, quando contatamos individualmente os informantes para arbitragem dos conteúdos sintetizados de cada comunidade, ou seja, a validação dos resultados da coleta de dados, a crise sanitária provocada pela Covid-19 imprimia mudanças significativas nas comunidades. Apesar de revisarem planos, tanto comunais quanto individuais, restou evidente que ideais de vida e de militância ambiental e social foram reforçados, tanto no interior quanto no entorno das comunidades.

Nos contatos remotos, os informantes destacaram restrições socioeconômicas e sustentaram, espontaneamente, que se sentiam protegidos, uma vez que a subsistência tem dependência maior de trabalho direto no local e menos na interação com o exterior. A crise sanitária, assim, reafirmou valores de vida em equilíbrio com ecossistemas, de cuidado coletivo e de satisfação com a escolha anteriormente feita. Os depoimentos corroboram a ideia de que as comunidades se orientam à reprodução social e que o trabalho para a autossuficiência, alimentar e habitacional principalmente, é fator determinante para relativizar dependências do mercado.

\section{Estrutura organizacional e processo decisório}

As ecovilas têm estrutura organizacional horizontal e flexível com processo decisório baseado em relações isonômicas entre membros. Abordamos essas duas categorias (Quadro 1) conjuntamente, tomando-as como categorias fundantes da gestão comunal, que se orienta por propósitos de autossuficiência e reprodução social. Não ocorre, nos dados coletados, manifestação de autoridade, de estrutura decisória hierarquizada. Ao contrário, predomina autonomia, evidenciando elementos de racionalidade substantiva na prática administrativa, traços comuns ao tipo ideal isonomia, conforme pontua Serva (1997). No conjunto, sintetizam a primeira das cinco características da isonomia de Guerreiro Ramos (1981) - atividades autogratificantes - com os membros participando de grupos que proporcionam um tipo generoso de relacionamento social

Na Campina, cada espaço coletivo é atribuído a um "focalizador", que tem a responsabilidade de mantê-lo em ordem, planejar e executar as tarefas requeridas informando o andamento aos demais. A Tibá igualmente ilustra processo decisório descentralizado com estrutura organizacional horizontal. Uma tibaense comentou que se tornara responsável por fazer as planilhas de gerenciamento, todavia mediante decisão coletiva:

Elaborei algumas ferramentas de gestão e propus ao grupo. Depois que aceitamos o procedimento, cada um ficou livre para tomar conta. Não é que eu sou o responsável; ninguém chega com uma nota de compra e me entrega para eu colocar na planilha. Todos têm autonomia.

Tal iniciativa é útil para ilustrar as outras quatro características da isonomia (Ramos, 1981): prescrições mínimas e, quando necessário, estabelecidas por consenso; atividade realizada como vocação - no caso, derivada de conhecimento técnico de um membro; sistema de tomada de decisão e de fixação de diretrizes políticas 
totalmente abrangente. A passagem acima revela que as ferramentas sugeridas foram previamente acatadas e são geridas coletivamente; relações primárias entre os membros - em contraposição a relações formais hierarquizadas - viabilizadas por estrutura organizacional flexível, horizontal, e processo decisório entre iguais.

A Tibá formou um grupo de cinco pessoas, o Basal, responsável por áreas comuns e ações cotidianas. É um empreendimento coletivo de pequeno porte, o que, na concepção de Guerreiro Ramos (1981), é fenonomia, "sistema social iniciado e dirigido por um indivíduo, ou por um pequeno grupo, e que permite a seus membros o máximo de opção pessoal e um mínimo de subordinação a prescrições operacionais formais” (p. 152). Uma tibaense comenta a respeito:

Dividimos em áreas organizacionais. Para os residentes [grupo Basal], decidimos as demandas que nos interessam e os projetos a desenvolver, como plantações, programas de estágio e visitantes, eventos, cursos. Assim formamos uma organização separada dos não residentes. Para o grupo da Tibá [que inclui membros não residentes], decidimos funções gerais como os projetos a longo prazo, infraestrutura em geral. Quem mora fora não tem responsabilidade para as coisas diárias, mas com o todo; os residentes têm mais para o diário, e a carga do geral fica dividida. Antes tínhamos mais interferências de um grupo no outro nesses pontos.

Localizamos aqui elemento de racionalidade instrumental - divisão de trabalho - com implicações nas relações interpessoais e no compromisso com o meio ambiente natural. A expressão da tibaense diferencia membros residentes de não residentes. Conflitos estiveram e estão presentes, nessa diferenciação, uma vez que "antes tínhamos mais interferências de um grupo no outro". Todavia, não se trata de indivíduos divergindo em torno de interesses individuais, mas sim de propósitos coletivos.

Se havia interferências de um grupo no outro, o diálogo ocorreu para reduzir danos, respaldado no dispositivo de que as decisões, na Tibá, "são tomadas por consenso e não por voto. Não é a maioria que ganha e isso é a nossa sociocracia”. Identificamos, na decisão reportada, predominância - e não exclusividade - de racionalidade substantiva na resolução de conflito, em processo de divisão do trabalho. Ratifica-se, assim, a escala de intensidades, o continuum mencionado por Serva (1997).

Source Temple e Campina apresentam estrutura e funcionamento mais espontâneos, o que não prescinde de medidas organizativas. Reuniões semanais entre residentes, voluntários e visitantes são realizadas na Campina para distribuir rotinas. Uma campineira registrou que "no início eram reuniões esporádicas e quase sempre para resolver problemas já acontecendo. Agora, fazemos antes desses problemas se tornarem reais”. Em pauta, sempre, o reforço à orientação para autossuficiência em meio a deliberações administrativas, evidenciando, mais uma vez, atos de cunho instrumental mediados por elemento de racionalidade substantiva - tais como julgamento ético e valores emancipatório (Serva, 1997).

Reuniões mensais, exclusivas para moradores da Campina, tratam de assuntos de mais longo prazo, mesmo estratégicos para a comunidade. Uma campineira registrou que, nessas reuniões, “falamos também sobre acordos de convivência. Alguns pensamos por muito tempo até uma decisão. Outros deixam de existir. A coisa vai se fazendo". Outros assuntos, como a aceitação de novos moradores e mitigação de conflitos, também estão presentes. A partir desse esquema de reuniões, um processo de resolução de conflitos foi delineado.

Quando existe um conflito entre moradores, estabelece-se comunicação direta entre as partes ou os litigantes, visando à conciliação sem a intermediação de terceiros. Quando não concretizada a conciliação, um 
mediador passa a atuar. Uma campineira observou que "mais de $50 \%$ dos casos são resolvidos no primeiro estágio". Se, nas duas fases iniciais, o conflito persistir, convoca-se reunião para decisão colegiada. Mas "raramente chegamos a esse ponto” - registra uma campineira. Tal processo de decisão, dialógico, Tenório (2005) emprega para qualificar a gestão social.

Nas ecovilas ocorrem, conforme identificou Siqueira (2012), lógicas mais ou menos formais. Floresta de Iroko e Tibá têm regras com caráter mais formal, fenômeno explicado por propósitos semelhantes na origem, que imputamos ao tipo de organização estruturada mediante aquisição de cotas. Apesar das regras, há flexibilidade nas condições técnico-organizativas, que estão sempre submetidas a (re)formulações via diálogo coletivo. 0 registro de uma floresteira, ao apontar adequações internas às vocações dos membros - quesito caracterizador da isonomia (Ramos, 1981) - ilustra tal flexibilidade: "Foi chegando biólogo, ecologista, agrofloresteiro; nessas áreas temos bastante gente. Ainda não chegou um administrador que seja mais familiarizado com as coisas mais burocráticas”.

No conjunto, a razão de ser de cada comunidade compreende - além do cuidado com o ecossistema - a constituição de ambiente social de apoio mútuo e relações entre iguais, em sintonia com o conceito de isonomia de Guerreiro Ramos (1981). O processo decisório, então, é responsável por encadear trabalhos individuais realizados sob autonomia e vocações, viabilizando autorrealização e atribuindo caráter de isonomias, de organizações substantivas (Serva, 1997).

\section{Relações econômicas plurais e as trocas sociais}

Os processos de gestão comunal, fundamentados em atividades de trabalho e produção realizadas como vocação, conciliam autonomia com interesses e habilidades profissionais não sob a forma de esforços exclusivamente técnico-econômicos. Ensejam horizontalidades na tomada de decisão que, uma vez mediada por elementos de racionalidade substantiva e um modo peculiar de vida que integra ser humano e meio ambiente natural, determina a gestão comunal. É, pois, a gestão comunal que viabiliza situações de trabalho e tempos individuais internamente sincronizados e que, assim, é útil à preservação da autonomia dos membros, inclusive em termos de decisões de caráter econômico-financeiro não vinculadas à comunidade. Pontua uma tibaense:

O desafio é criar condições para que as pessoas possam, independentemente da forma, se trabalhando fora ou não [...] usufruir da vida na Tibá. Alguém pode ser feliz comendo a mandioca que plantou, outro quer ganhar 20 mil por mês. Aí vai de cada um. 0 importante é a valorização do espaço e do nosso trabalho para praticar o nosso modo de vida.

O compromisso de "valorização do espaço e do nosso trabalho para praticar o nosso modo de vida" remete os membros, internamente, a um padrão de autarquia, à domesticidade de Polanyi (2000). É um fazer econômico com vistas a garantir dado estilo de vida. A domesticidade ancora-se em propósitos de regeneração do ecossistema e conecta-se a ideias de sustentabilidade, a SSAN e saúde coletiva. Fomenta, portanto, capacidades criativas, razão crítica e autonomia. A autonomia revela-se não apenas em processo decisório coletivo, mas também em escolhas econômicas individuais, conforme registra a tibaense. Esse fenômeno ratifica achado de Cunha (2012), que igualmente identificou a coexistência entre iniciativas individuais e coletivas dentro de ecovilas.

Na Floresta de Iroko, devido à estruturação em lotes, a independência nos interesses individuais é mais evidente, de modo que cada membro goza de ampla autonomia em sua área. À medida que vários projetos individuais avançam, surgem demandas de harmonização entre autonomia e cooperação, sem embaraços à gestão 
comunal, como comenta uma floresteira: "A gente sabe que, quando as pessoas se instalam aqui, começam a produzir e ganhamos força. Já temos muitos planos em conjunto. Claro que eu tenho os meus, mas tudo se encaixa”. Na Source Temple Sanctuary, ocorre fenômeno similar entre autonomia e cooperação:

Quando alguém quer assumir algo novo, como hospedagem, nós apoiamos. Já tivemos hospedagem, temos várias casas que podem servir para isso. Mas depois de um tempo a pessoa responsável não quis mais e tudo bem. Restaurante para fora foi outro caso. Quando alguém quer e sente que deva fazer, está livre para fazer. Nós, como grupo, pensamos em apoiar as ideias e a coisa vai-se construindo naturalmente.

Autonomia econômica "vai-se construindo naturalmente", baseada em atividades produtivas tanto para suprimento de necessidades coletivas quanto para o atendimento a interesse individuais. Assim, além de produção interna para as famílias e o coletivo, o que configura domesticidade, há serviços e produção de excedentes conectando a comunidade ao mundo exterior em relações de mercado e trocas sociais, estas sob acordos voluntários que Polanyi (2000) denomina reciprocidade. Esclarece uma templária:

Sempre compramos ou trocamos com nossos vizinhos o que não produzimos aqui. Temos nossa horta que nos supre de salada e muitas outras coisas. Mas pegamos muitas frutas e queijos com eles. É uma maneira de ajudar eles. Aqui na região, os vizinhos produzem praticamente só leite e queijo para vender, mas sempre eles têm um pomar e uma horta para consumo da família.

Na Tibá, a partir de 2013, o número de moradores cresceu, chegando a mais de 40, incluindo os "flutuantes" - aqueles sem compromisso de permanência. Adveio, assim, a iniciativa de atrair pessoas para atividades produtivas mediante prática de inserção via "aproximação pelo trabalho". Tensões entre as racionalidades instrumental e substantiva, conforme pontuado por Siqueira (2012), estão postas - como ilustra o caso de locação de uma casa e um hectare para uma pessoa que já esteve na comunidade em processo de inserção e que, após sair, retornou, se aproximando dessa forma. Trata-se de aluguel que teve carência de seis meses para início do pagamento com "dinheiro vai para o caixa comum; ele sabe plantar e estava procurando terra, então, conversamos e chegamos a esse acordo", afirma uma tibaense, "de bom senso [a carência] porque temos que esperar a plantação crescer e ele já começou a colocar as hortaliças na nossa banca da feirinha de sábado. Fica melhor para todos, para fortalecer toda a comunidade".

O caso acima ilustra, por um lado, reciprocidade - de conhecimentos e produtos sob padrão de simetria (Polanyi, 2000) - e, por outro, dilema na concretização de racionalidade substantiva (Serva,1997), que emerge impulsionada por elemento de racionalidade instrumental, ou seja, pela necessidade de aluguel como fonte de renda. Nos trechos destacados, impasses derivam da necessidade de atrair pessoas para o coletivo e de consentir retorno de ex-membro.

Reciprocidade mediada por relações de mercado revela-se, ainda, em outro aluguel - de instalações para projeto de meliponicultura. Nesse caso, colmeias estão espalhadas na comunidade, e o mel é comercializado pelos meliponicultores sem relação direta com a comunidade - revelando relações de mercado. Benefícios, porém, ocorrem pelo aumento da polinização das áreas de cultivo e da mata nativa residual, revelando relação 
de reciprocidade via cooperação em atividade que é, simultaneamente, ecológica e técnico-econômica - novamente, requerendo ponderações entre racionalidade substantiva e racionalidade instrumental.

Outra evidência de pluralidade econômica, via processos de inclusão de membros, ocorre na Campina. Qualquer visitante, caso deseje, pode ser incorporado à vida comunitária por vocação e interesse próprio, desde que atendendo motivações gerais da comunidade. Para tal, a pessoa interessada passa por período de inclusão de 12 meses sob o status de demorador. Nesse período, o(a) demorador(a) contribui financeiramente para o caixa comum e começa a receber responsabilidades cotidianamente. A contribuição financeira custeia moradia e refeições realizadas coletivamente. Nas palavras de uma campineira: "No tempo que a pessoa fica como demoradora, nas reuniões de moradores sempre é avaliada".

Uma campineira detalha aprendizagens coletivas entre moradores e demoradores, numa espécie de acolhimento: "A gente quer fortalecer a comunidade, por isso, damos atenção ao desenvolvimento de quem está aqui, vivendo, experimentando o dia a dia". Se aceita, a pessoa pode construir habitação, cuja posse é comunitária. Esse aspecto é de conhecimento de todos desde o princípio e, a partir da aceitação, conforme comenta informante da comunidade, a pessoa entra no ciclo econômico solidário e passa a receber renda gerada pela Campina.

\section{Agricultura natural}

O conceito de agricultor como a pessoa que cuida da terra é revelado na gestão comunal e possibilita entender relações das comunidades pesquisadas com o ecossistema. Diferentemente do monocultor que produz mercadorias agrícolas, o cultivo em sistema agroflorestal, observado nas comunidades, aproxima seres humanos, fauna e flora em cuidados recíprocos. Além de prover alimentos, os plantios regeneram a vida no solo, subsidiando equilíbrio do ecossistema e influenciando militância ambiental no entorno. Na Campina, a agrofloresta serve como barreira às queimadas. Na Tibá, é resistência à monocultura da cana-de-açúcar. Floresta de Iroko reúne agricultores em rede e apregoa que o cacau pode ser plantado em consórcio com outras plantas, em meio à floresta e na sombra. A Source Temple amplia interlocuções com a vizinhança para além da pauta espiritual a partir da ecologia.

É nítida a customização da produção, sempre baseada em vocações locais. Na monocultura, qualquer que seja o cultivar, em qualquer parte do mundo, a padronização transforma o ato produtivo em rotinas simplificadas e repetitivas, removendo do agricultor a condição de mentor intelectual do processo produtivo (Shiva, 2003). Em contrapartida, nas ecovilas, os processos de produção são permanentemente instigantes, mediante técnicas e experimentações de cultivos integradas à natureza, baseadas em processos internos e em noções de sistemas autossuficientes. Rompe-se, assim, com o padrão hegemônico de produção agrícola - o que exige esforços ampliados de gestão comunal na preservação da diversidade da vida - e a dependência do mercado, mitigada por trabalhos comunais que asseguram traços emancipatórios (Serva, 1997).

A gestão comunal está orientada a prover, além de necessidades humanas, condições de preservação e regeneração de ecossistemas. A produção de alimentos associa demandas comunitárias com alternativas de policultivos e de SSAN baseadas em processos, não em insumos. A gestão comunal orienta o trabalho e a produção nesse sentido. Uma templária comenta que "todos os banheiros secos que temos aqui nos fazem ter bom adubo sem precisar comprar de fora. Para isso é preciso manejá-lo, e não ir ao mercado comprar adubo". Além de prover alimentos, uma campineira comenta que a floresta agora recuperada atende múltiplas demandas: 
Coletamos varas de madeira para uma casa de pau a pique. Recuperamos a área e agora temos disponíveis os materiais. Faz parte do manejo, não é degradante. Mesmo caso da lenha: colhemos as madeiras secas da mata, além de diminuir o risco de incêndio, usamos na cozinha.

Em contraposição a práticas hegemônicas dependentes do mercado - para suprimento de matérias-primas, insumos, equipamentos e comercialização - as ecovilas apresentam-se não apenas como movimento ecológico, de resistência à degradação socioambiental, mas também como organizações substantivas centradas na busca por meios e finalidades de autossuficiência. Uma campineira comenta: "Nosso maior gasto é com as refeições e com alimentos que não conseguimos produzir aqui”. A gestão comunal, portanto, tenta lidar com múltiplas demandas para promover a autossuficiência, principalmente alimentar e de moradia, ao mesmo tempo que cria condições para que, a exemplo dos princípios da agrofloresta, a vida comunal progrida sob processos e interações sintrópicas e não dependentes do mercado.

\section{CONSIDERAÇÕES FINAIS}

As ecovilas são ambientes que reconfiguram noções hegemônicas de organizações privadas, gestão, trabalho, economia e vida social. A gestão comunal emerge nesse contexto articulando a orientação à reprodução social das ecovilas, a uma estrutura organizacional horizontal flexível, com processos decisórios isonômicos, trocas sociais entre seres humanos, e destes com o meio ambiente natural, intencionadas à autossuficiência via práticas de agricultura natural.

Ainda que submetidas a conflitos, impasses e contradições, as ecovilas ressignificam o ato administrativo em organizações privadas pela resiliência à vida utilitária, mercadocêntrica, porém sem negá-la. Conflitos ocorrem em torno de decisões para benefício comum e não de ganho individual imediato. Contradições revelam-se por interações com o mercado - a exemplo de comercialização de excedentes, aluguel de instalações e arrecadações monetárias em programas de visitação. À medida que as reais intenções de cada comunidade são absorvidas claramente pelos moradores das ecovilas, os impasses tendem a diminuir. Técnicas de comunicação direta e não violenta, como na Campina, estatutos bem-definidos, como na Floresta de Iroko e Tibá, e mesmo a falta de acordos formais, porém com pactos comunais claros, como na Source Temple, são ações propositivas nessa direção.

Os propósitos, valores e compromissos de cada ecovila fundem-se em um todo organizacional que passa a demandar o que designamos gestão comunal, caracterizada pela predominância de racionalidade substantiva. Compõem movimento ecológico de resistência via práticas de agricultura natural e forma organizacional que estrutura trabalho e produção para a autossuficiência mediante relações econômicas de reciprocidade e domesticidade intercaladas com as de mercado. Viabilizam, assim, autorrealização, entendimento, julgamento ético, autenticidade, valores emancipatórios e autonomia (Serva, 1997).

As ecovilas pesquisadas concretizam práticas de preservação/regeneração de ecossistemas contrapondo-se à lógica de mercado. Rejeitam a monocultura agrícola em prol da agricultura natural e de sistemas biodiversos. Em termos de gestão, predominam processos decisórios isonômicos, com participação ativa dos membros da tomada de decisão a sua execução.

0 trabalho associado supera interesses exclusivamente ecológicos, caracterizando dado padrão de sociabilização humana que, conforme pontua Comunello (2016), reage à crise ambiental por meio de princípios diversos 
e visão sistêmica de mundo e de relação natureza/ser humano. Assim, as ecovilas também merecem atenção como organizações produtivas privadas pelo fato de conciliarem interesses humanos de trabalho e produção a práticas econômicas plurais que envolvem concepções de cooperação e mutualismo.

Em momento de crise sanitária global, como consequência da Covid-19, ecovilas edificam ambientes alternativos de aprendizagens e de vida em sociedade, principalmente pela centralidade no apelo da integração ser humano/meio ambiente natural. Importantes respostas para problemas cotidianos estão em andamento, conforme apontam os resultados, fomentando novas institucionalidades de inspiração popular e de mitigação de passivos ambientais, o que gera subsídios também para a administração pública e políticas governamentais. Tais unidades apresentam, por exemplo, potenciais para funcionamento como unidades formativas e demonstrativas de serviços de assistência técnica e extensão rural (ATER) com viés agroecológico.

Como exemplos práticos de organizações substantivas que se constituem com base em interesses ecológicos, as ecovilas trazem contribuições para a Ciência Administrativa que ultrapassam as convencionais abordagens de organizações econômicas privadas. Fomentam, via interações intercomunitárias, mutualidades e práticas econômicas plurais que incluem o enclave mercado sob formatos de isonomias/fenonomias (Ramos, 1981).

A partir dos resultados alcançados, podemos indicar lacunas para estudos futuros. Nesse quesito, tornam-se pertinentes pesquisas relacionadas à compreensão das ecovilas como comunidades de práticas (CoPs) (Wenger, 1998), sob a abordagem do desenvolvimento social e interorganizacional (Fischer \& Melo, 2003) e como empreendimento econômico solidário com práticas de finanças solidárias.

\section{REFERÊNCIAS}

Altieri, M. (1998). Agroecologia: A dinâmica produtiva da agricultura sustentável. Porto Alegre, RS: Editora da UFRGS.

Antunes, R. (2018). O privilégio da servidão: O novo proletariado de serviços na era digital. São Paulo, SP: Boitempo.

Araujo, G. E. F., Paiva, J. A. de, Souza, W. J. de, \& Momo, D. C. (2013). Economia solidária à luz do ambiente isonômico de Guerreiro Ramos: Vivências do 'Grupo de Mulheres Decididas a Vencer'. Revista Eletrônica de Ciência Administrativa, 12(1), 58-74. doi: 10.5329/RECADM.2013007

Barros, C. F. P. (2007). Trocas, hierarquia e mediação: As dimensões culturais do consumo em um grupo de empregadas domésticas (Tese de doutorado, Universidade Federal do Rio de Janeiro, Rio de Janeiro, RJ).

Birochi, R., Vivan, C., \& Granzotto, A. C. de B. (2019). As faces divergentes das organizações em redes agroalimentares. Raízes: Revista de Ciências Sociais e Econômicas, 39(1), 114132. doi: 10.37370/raizes.2019.v39.85

Carlsen, A., Clegg, S. R., Pitsis, T. S., \& Mortensen, T. F. (2020). From ideas of power to the powering of ideas in organizations: Reflections from Follett and Foucault. European Management Journal, 38(6), 829-835. doi: 10.1016/j.emj.2020.03.006

Comunello, L. N. (2016). Aprendizagem e espiritualidade em Ecovilas: Quando "o Universo todo ensina" (Tese de doutorado, Pontifícia Universidade Católica do Rio Grande do Sul, Porto Alegre, RS).
Cunha, E. V. (2012). A sustentabilidade em ecovilas: Práticas e definições segundo o marco da economia solidária (Tese de doutorado, Universidade Federal da Bahia, Salvador, BA).

Dawson, J. (2004). Wholesome living exploring the connections of the ecovillage movement. Resurgence-London-Navern Road, 225, 36-43.

Elliott, R., \& Jankel-Elliott, N. (2003). Using ethnography in strategic consumer research. Qualitative Market Research, 6(4), 215-223. doi: 10.1108/13522750310495300

Fischer, T., \& Melo, V. P. (2003). Gestão social do desenvolvimento e interorganizações. XII Colóquio Internacional sobre Poder Local, Salvador, BA, UFBA.

Flick, U. (2008). Introdução à pesquisa qualitativa. Porto Alegre, RS: Artmed Editora.

Gilman, R. (1991). Ecovillages and sustainable communities: A report for Gaia Trust by Context Institute.

Han, B. C. (2017). Sociedade do cansaço. Porto Alegra, RS: Editora Vozes Limitada.

Mariampolski, H. (1999). The power of ethnography. Journal of the Market Research Society, 41(1), 75-86. doi: 10.1177\%2F147078539904100105

Moisander, J., \& Valtonen, A. (2006). Qualitative marketing research: A cultural approach. London, Sage. 
Pinheiro, L. V. de S. (2019). Rompendo cercas, construindo saberes: Trabalho agroecológico, vivência e (re)significações nas relações com o lugar (Tese de doutorado, Universidade Federal do Rio Grande do Norte, Natal, RN).

Polanyi, K. (2000). A grande transformação: As origens da nossa época. Rio de Janeiro, RJ: Editora Campus.Pinheiro, L. V. de S. (2019). Rompendo cercas, construindo saberes: trabalho agroecológico, vivência e (re)significações nas relações com o lugar. 232f. Tese de Doutorado, Universidade Federal do Rio Grande do Norte, RN, BR

Ramos, A. G. (1981). A nova ciência das organizações: Uma reconceituação da riqueza das nações. Rio de Janeiro, RJ: Editora da FGV.

Santos, S. J., Jr. (2006). Ecovilas e comunidades intencionais: Ética e sustentabilidade no viver contemporâneo. III Encontro da ANPPAS, Brasília, DF.

Serva, M. (1993). O fenômeno das organizações substantivas. RAERevista de Administração de Empresas, 33(2), 36-43. doi: 10.1590/So034-75901993000200005

Serva, M. (1997). A racionalidade substantiva demonstrada na prática administrativa. RAE-Revista de Administração de Empresas, 37(2), 18-30. doi: 10.1590/So03475901997000200003

Serva, M., Caitano, D., Santos, L., \& Siqueira, G. (2015). A análise da racionalidade nas organizações: Um balanço do desenvolvimento de um campo de estudos no Brasil. Cadernos EBAPE.BR, 13(3), 414-437. doi: 10.1590/1679-395116344

Silva, É. S. Da, \& Silva, G. P. Da. (2020). Formação humana e racionalidade substantiva: Resistência à formação instrumental. Plurais Revista Multidisciplinar, 4(3), 115-131. doi: 10.29378/plurais.2447-9373.2019.v4.n3.115-131

Sinisterra, M. L. C. (2013). Circulando no sagrado: Tradições, rituais e cerimônias ancestrais na vida moderna - Uma experiência na ecoaldeia La Atlantida em Cajibio-CaucaColômbia (Tese de doutorado, Universidade Federal Fluminense, Rio de Janeiro, RJ).
Siqueira, G. de M. V. (2012). Tensão entre as racionalidades substantiva e instrumental na gestão de ecovilas: Novas fronteiras do campo de estudos (Dissertação de mestrado, Universidade Federal de Santa Catarina, Florianópolis, SC).

Siqueira, G. de M. V. (2017). Tensão entre as racionalidades substantiva e instrumental: Estudo de caso em uma ecovila no sul da Bahia. Cadernos EBAPE, 15(4), 768-782. doi: 10.1590/1679-395155014

Shiva, V. (2003). Monoculturas da mente. São Paulo, SP: Editora Gaia.

Souza, M. F. de (2016). Além da Escola: reflexões teóricometodológicas com base na análise de práticas educativas alternativas descobertas em áreas rurais da região de São Carlos S.P. (Tese de doutorado, Universidade Estadual Paulista, São Carlos SP.)

Tenório, F. G. (2005). (Re)visitando o conceito de gestão social. Desenvolvimento em Questão, 3(5), 101-124. doi: $10.21527 / 2237-6453.2005 \cdot 5 \cdot 101-124$

Tres, G. S. \& Souza, W. J. de. (2019). La naturaleza epistemológica de las ecovilas: Revisión sistemática en las tesis defendidas en programas de postgrado en Brasil. RIPS: Revista de Investigaciones Políticas y Sociológicas, 18(2), 137-155. doi: 10.15304/rips.18.2.5407

Tenório, F. G. (2014). In B, Cavalcante, Y. Duzert, \& E. Marques, Guerreiro Ramos, coletânea de depoimentos. 43-48, Rio de Janeiro: FGV Editora.Tenório, F. G. (2005). (Re) visitando o conceito de gestão social. Desenvolvimento em questão, 3(5), 101-124.

Tres, G. S., \& Souza, W. J. de. (2019). La naturaleza epistemológica de las ecovilas: Revisión sistemática en las tesis defendidas en programas de postgrado en Brasil. RIPS: Revista de Investigaciones Políticas y Sociológicas, 18(2), 137-155. doi: 10.15304/rips.18.2.5407

Weber, M. (1994). Economia e sociedade (Vol. 1, 3a ed.). Brasília, DF: Editora UnB.

Wenger, E. (1998). Communities of practice: Learning, meaning and identity. Cambridge, UK: Cambridge University.

Yin, R. K. (2015). Estudo de caso: Planejamento e métodos (5a ed.). Porto Alegre, RS: Bookman.

\section{CONTRIBUIÇÃO DE AUTORIA}

Guilherme Smaniotto Tres trabalhou na conceitualização e abordagem teórica-metodológica. A revisão teórica foi conduzida por Guilherme Smaniotto Tres e Washington José de Souza. A coleta de dados foi realizada por Guilherme Smaniotto Tres. Par-ticiparam da análise de dados Guilherme Smaniotto Tres e Washington José de Souza. Todos os autores participaram da redação e revisão final do manuscrito. 